\title{
European Strategic Energy Technology Plan
}

\author{
Redondo Gil, C. ${ }^{\text {; }}$ Esquibel, L.A.; Alonso Sánchéz, A.M. and Zapico, P. \\ ${ }^{1}$ Electrical Engineering \& \\ Systems Engineering and Automatic Control Department \\ Faculty of Industrial and Computer Engineering, University of León. 24071-León (Spain). \\ Phone.: +34 987291786 carlos.redondo.gil@unileon.es
}

\begin{abstract}
The European Commission has adopted a proposal for a European Strategic Energy Technology Plan [1]. Energy technology will be a key element of Europe's plans to reduce its greenhouse gas emissions and move towards a low-carbon future. But there are structural weaknesses in the current energy research system [2]. The Strategic Energy Technology Plan [3] should help the European Union position itself to develop the technologies it needs to meet its political objectives and at the same time ensure its companies can benefit from the opportunities of a new approach to energy.
\end{abstract}

\section{KEY WORDS}

Energetic policy of the European Union. Policy of $\mathrm{R}+\mathrm{D}+\mathrm{i}$. Strategic Energy Technology Plan.

\section{Introduction.}

The Strategic Energy Technology Plan proposes a number of concrete actions to develop a more coherent energy research landscape in Europe. These include:

- Creating European Industrial Initiatives, which will strengthen energy research and innovation by bringing together appropriate resources and actors in a particular industrial sector. They will have measurable objectives in terms of cost reduction or improved performance, and will bring together the efforts of the EU-level, Member States and industry. They will be focused on technologies for which the barriers, scale of investment and risk can best be tackled collectively. Areas for this approach that arose out of the consultation process are: Wind; solar; bio-energy; $\mathrm{CO}_{2}$ capture, transport and storage; electricity grids; and nuclear fission.

- Creating a European Energy Research Alliance, to enable greater co-operation across Europe of the research work going on in universities, research institutes and specialised centres. The Alliance will be able to cover the multitude of scientific disciplines that have an impact on the development of energy technologies (physics, chemistry, materials science, engineering and so on). Area for focus could include basic energy science, enabling \& breakthrough technologies and advanced energy efficiency.
- Planning the transition of European energy infrastructure networks and systems: a sustainable, interconnected European energy system will require massive change to infrastructures and systems. Not only will this process require significant investment, and take time, perhaps decades, it will also affect many different sectors. Therefore a clear view is needed of how this is done, to make the most of an integrated low-carbon energy system across Europe. The Commission will develop its ideas in this area in 2008.

- European Energy Technology System: one of the weaknesses of the current system is the lack of reliable data on energy technologies. The Commission will establish and run a regularly up-dated information system, open to all, which will map technologies - providing information on the latest situation, barriers to technological uptake and the potential of existing technologies. It will also provide up to date information on financial and human resources. Such a system will allow rigorous monitoring of the progress in the development of European energy technologies and provide useful support to policy-making.

- Creating a European Community Steering Group on Strategic Energy Technologies, which will allow Member States and the Commission to plan joint actions and coordinate policies and programmes[4]. A European Energy Technology Summit in 2009 will provide an opportunity to review progress and make achievements known within the wider energy technology sector.

\section{Energy Policies versus Energy Technology.}

To exist, in the current geopolitical frame a deep interrelation between the challenges linked to the climate change, the necessary safety of energy supply and you her rule derivatives of the markets in competition that necessary need a coordinated answer. It is necessary to coordinate the targets proposed in energy matter, the 
targets related to the environmental politics and the strategic macroeconomic targets foreseen by the EU (reduction for 2020 hothouse gas emission in $20 \%$ and to assure $20 \%$ of renewable energy sources in the energy consumption of the Strategic Energy Technology of the European Union; reduction in the Strategic Energy Technology of the European Union of the use of primary energy in $20 \%$ in 2020; delimitation of the prices of the coal for the Emission Commercial Scheme and taxes of energy; I design and develop of a Market of Energy competitive Intern and definition and development of a politics of international energy. The technological development and the innovation are essential in the attainment of the proposed targets. It is obligatory to design a politics faced to accelerate the development and the deployment of efficient technologies of coal. The fulfillment of the targets foreseen for 2020, it has to optimize the costs of production of the clean energy and guarantee that the industry of the European Union is located in the avant-garde of the technological sector of the coal of low levels of emission of $\mathrm{CO}_{2}$. Even more, fixed for 2050 a target of reduction of the levels of gas emission of greenhouse effect between 60 and $80 \%$ is necessary the development of a politics decided on the subject of Research that guarantees the success in the development of new generations of technological.

\section{The State of the Art of the Energetic Technology at present.}

Since the fall of prices of oil in the 70s, Europe has had access to an energy source reasonably cheap and abundant. The availability of resources, the consumption without coal restrictions and the inherent mechanisms at the beginning of the free market they have determined the dependency on the fossil fuels and have bordered for the investment and the innovation in new energy technologies. It exists for it neither in the current moment nor a natural market, nor a short-term competitive advantage for the above mentioned technologies. It is for it necessarily to arbitrate mechanisms to a great extent based on the public intervention to guarantee the development of the innovation of energy matter.

The investments in research [5], both public and deprived of the European Union, in energy matter have diminished perceptibly from the $80 \mathrm{~s}$. It has provoked a reduction in the capacity of development of infrastructures and of the technological innovation in the energy sector. To place them in the relative levels of investment of the $80 \mathrm{~s}$ it would be necessary to multiply by four the current quantity destined for research and development. The innovation process in the ambience of the energy technology and the capacity of penetration of the new energy sources the markets is characterized by clear structural weaknesses: the external economies of technological character and his associate social costs $\left[{ }^{6}\right]$, the difficulty of access to a market of masses, the quantity of the required investments, the scarce technological development and the regulation of the traditional systems of energy production. The new energy technologies are generally more expensive than the traditional sources and not necessary they provide, beforehand, a better service.

\section{Strategic aspects for the development of the Energy Technology.}

The fulfillment of the targets proposed for 2020 they need: (1) to support the research with the object of optimizing costs and improving the efficiency and (2) to facilitate the development of a competitive market and to favor the elimination of not technological barriers that make the technological development and the innovation difficult.

To obtain the targets of reduction of gas emission of greenhouse effect foreseen for 2050 a new generation of energy technologies is essential to develop even with the forecast of which some of them will not have an enclosed significant impact in 2020. It is therefore necessary to establish new organizational models and to provide to the industry of the necessary infrastructures and in line with the proposed targets.

Key aspects of the Technology to develop during the next 10 years to reach the 2020 targets.

- Make second generation bio-fuels competitive alternatives to fossil fuels, while respecting the sustainability of their production;

- Enable commercial use of technologies for $\mathrm{CO}_{2}$ capture[7], transport and storage through demonstration at industrial scale, including whole system efficiency and advanced research;

- Double the power generation capacity of the largest wind turbines, with offshore wind as the lead application;

- Demonstrate commercial readiness of largescale Photovoltaic (PV) [8] and Concentrated Solar Power;

- Enable a single, smart European electricity grid able to accommodate the massive integration of renewable and decentralised energy sources;

- Bring to mass market more efficient energy conversion and end-use devices and systems, in buildings, transport and industry, such as polygeneration and fuel cells;

- Maintain competitiveness in fission technologies, together with long-term waste management solutions;

Key aspects of the Technology to develop during the next 10 years to reach the 2050 vision:

- Bring the next generation of renewable energy technologies to market competitiveness;

- Achieve a breakthrough in the cost-efficiency of energy storage technologies;

- Develop the technologies and create the conditions to enable industry to commercialise hydrogen fuel cell vehicles; 
- Complete the preparations for the demonstration of a new generation (Gen-IV) of fission reactors for increased sustainability;

- Complete the construction of the ITER fusion facility and ensure early industry participation in the preparation of demonstration actions;

- Elaborate alternative visions and transition strategies towards the development of the TransEuropean energy networks and other systems necessary to support the low carbon economy of the future;

- Achieve breakthroughs in enabling research for energy efficiency: v.g. materials, nano-science, information and communication technologies, bioscience and computation [9].

\section{European Commission proposing.}

The Strategic Energy Technology Plan proposes to deliver the following results: a new joint strategic planning, a more effective implementation, an increase in resources, and a new and reinforced approach to international cooperation.

1) Joint strategic planning will enable a better orientation of efforts and would be the seed to bring together our researcher and our industry.

On 2008 the Commission establish a Steering Group on Strategic Energy Technologies to steer the implementation of the Strategic Energy Technology Plan, reinforcing the coherence between national, European and international efforts. The Group, chaired by the Commission, will be composed of high level government representatives from Member States.

In the first half of 2009, to review progress the Commission will organise a European Energy Technology Summit that will bring together all stakeholders in the entire innovation system, from industry to customers, as well as representatives of the European institutions, the financial community and our international partners.

To support the definition of energy technology objectives, as well as to build consensus around the Strategic Energy Technology Plan programme, the Commission will establish an openaccess information and knowledge management system on energy technologies.

2) For effective implementation we need more powerful mechanisms that can leverage the potential of European industry and researchers.

In 2008 the Commission proposed to launch six new European Industrial Initiatives that will target sectors for which working at Community level will add most value technologies for which the barriers, the scale of the investment and risk involved can be better tackled collectively.

The initiatives are as follows:
- European Wind Initiative: focus on large turbines and large systems validation and demonstration (relevant to on and off-shore applications).

- Solar Europe Initiative: focus on large-scale demonstration for photovoltaics and concentrated solar power

- Bio-energy Europe Initiative: focus on next generation bio-fuels within the context of an overall bio-energy use strategy.

- European $\mathrm{CO}_{2}$ capture, transport and storage initiative: focus on the whole system requirements, including efficiency, safety and public acceptance, to prove the viability of zero emission fossil fuel power plants at industrial scale.

- European electricity grid initiative [10]: focus on the development of the smart electricity system, including storage, and on the creation of a European Centre to implement a research programme for the European transmission network.

- Sustainable nuclear fission initiative: focus on the development of Generation-IV technologies [11].

Several initiatives that are already being implemented, or are well advanced in their preparation, serve as illustrative examples: the European fusion research programme [12] and its flagship 'ITER'; the Single European Sky air traffic management research programme (SESAR [13]); the proposed Joint Technology Initiative on Fuel Cells and Hydrogen [14]; and the proposed 'Clean Sky' Joint Technology Initiative on the environmental impacts of aviation.

To bring about a move from today's model of collaborating on projects towards a new paradigm of implementing programmes and to align these programmes with the Strategic Energy Technology Plan priorities, the Commission proposes to create a European Energy Research Alliance [15].

The European Institute of Technology [16] could provide an appropriate vehicle to realise this ambition, through a Knowledge and Innovation Community on energy and climate change.

The Commission proposes to initiate in 2008 an action on European energy infrastructure networks and systems transition planning. It will contribute to optimise and harmonise the development of low carbon integrated energy systems across the EU and its neighbouring countries. It will help the development of tools and models for European level foresight in areas such as smart, bi-directional electricity grids, $\mathrm{CO}_{2}$ transport and storage [17] and hydrogen distribution [18].

\section{3) Resources.}

Implementation of the Strategic Energy Technology Plan will help overcome the fragmentation of the European research and innovation base, leading to a better overall balance between cooperation and competition. Encouraging more focus and coordination between 
different funding schemes and sources will help to optimise investment.

Two challenges need to be addressed: mobilising additional financial resources, for research and related infrastructures, industrial-scale demonstration and market replication projects; and education and training to deliver the quantity and quality of human resources required to take full advantage of the technology opportunities that the European energy policy will create.

At the end of 2008 the Commission presents a Communication on financing low carbon technologies that will address resource needs and sources, examining all potential avenues to leverage private investment, including private equity and venture capital, enhance coordination between funding sources and raise additional funds.

4) International cooperation should be a fundamental pillar in our European strategy.

It is necessary to adopt our international cooperation on energy technology to a new dimension. The measures proposed in the Strategic Energy Technology Plan (v.g. the Steering Group, European Industrial Initiatives and the European Energy Research Alliance) should bring about a reinforced international cooperation strategy. It is necessary also to ensure that the EU increasingly speaks with one voice in international forum, where appropriate, to achieve a more coherent and stronger partnership effect.

\section{Technology Map.}

The purpose of the Technology Map is to underpin the Strategic Energy Technology Plan Communication. Based on it the Strategic Energy Technology Plan proposes actions to accelerate low carbon energy technology development and deployment through European Industrial Initiatives. The Technology Map provides a quantification of the potential contributions of key technologies to:

- Environment, CO2 emission reductions;

- Security of Energy Supply, fossil fuel savings;

- and Competitiveness, changes in the cost of energy.

The following list enumerates the different technologies to be considered in the making of the Technology European Map:

- Wind power

- Solar Photovoltaics

- Concentrated solar power

- Solar heating and cooling

- Hydropower generation. Large HPP

- Hydropower generation: Small HPP

- Geothermal

- Ocean wave power

- Cogeneration of heat and power

- Zero emission fossil fuel power plants

- Nuclear fission power

- Nuclear fusion power generation
- Electricity networks (smart grids)

- Bio-fuels

- Hydrogen and fuel cells

The analysis of each of them implies defining: his description (sector - power generation, heat generation, district heating, industry, distribution and/or distribution , current market share and state of the art), the current and future potential share in the European energy demand (baseline scenario, potential penetration and potential breakthroughs), the barriers to penetration in the European energy market and the needs to realise its potential and the synergies with other technologies and sectors.

The most significant barriers, common to most of the technologies, are:

- Access to grid and Investments in grid infrastructure.

- Inflexible grid infrastructure.

- Cost of off-shore grid and unavailability of onshore grid.

- Lack of large-scale testing facilities.

- Disparate level of financial support.

- Lack of social acceptance.

- Lack of skilled professionals.

- Lack of financial incentives.

- Lack of institutional support.

- Lack of support for $\mathrm{R}+\mathrm{D}$ and Demonstration.

- Lack of coordinated research efforts.

- Equity shortage for $\mathrm{R}+\mathrm{D}$ development and Demonstration.

- Techno-economic issues.

- Lack of feed in support in most EU country.

- Equity shortage for demonstrating first of a kind project.

- Complex regulations and administration.

- Coherent financial support mechanisms.

- Appropriate regulations, standards, permit procedures $\mathrm{R}+\mathrm{D}$ support.

- International collaboration and centralisation of existing Knowledge.

- Vocational and training programmes.

- High cost of electricity.

- High cost of technology learning.

- Lack of dedicated engineering capacities and of private Investments.

- Administrative and legislative.

- Lack of overall EU nuclear strategy.

- Lack of harmonised regulations and standards.

- Future availability of suitably qualified scientists and engineers.

- How to define/share reinforcement and connection cost between stakeholders under discussion.

- Regulatory framework.

- Social oppositions.

On the other hand, the needs most emphasized in the economical and technological area of the energy, and that determine of direct form the basic guidelines of a strategic energy Technology plan are: 
- Increased $\mathrm{R}+\mathrm{D}$ and Demonstration public support.

- Focussed and co-ordinated $\mathrm{R}+\mathrm{D}$ and Demonstration programme at the EU level.

- Appropriate regulations, standards, permit procedures $\mathrm{RD}+\mathrm{D}$ support.

- Specialised education programmes.

- Development of a liberalised market.

- Financial incentives.

- Framework to facilitating exports.

- Upgrading of grid infrastructures and appropriate EU regulations for grid integration.

- Better coordination of financial support schemes across the EU.

- Coherent, harmonised and conducive regulation and administration frameworks across the EU.

- Coherent financial support mechanisms.

- Additional incentives.

- International collaboration and centralisation of existing Knowledge.

\subsection{Wind power.}

\section{Description}

1) Sector: Power generation.

2) Current market share: $3 \%$ of demand $\sim 50 \mathrm{GWe}$

installed capacity.

3) State of the Art.

Onshore wind: Commercialised. Offshore wind: Starting deployment.

\section{Potential}

1) Baseline scenario:

2020: $120 \mathrm{GWe}$

2030: $148 \mathrm{GWe}$

2) Potential penetration:

2020: $120 \div 180 \mathrm{GWe}$

2030: $168 \div 300$ GWe

3) Potential breakthroughs: Large scale testing to commercialisation, particularly for offshore environments.

\section{Barriers}

Inflexible grid infrastructure.

Lack of large-scale testing facilities.

Under-developed storage mechanisms.

Disparate level of financial support.

Lack of social acceptance.

Lack of skilled professionals.

\section{Needs}

Upgrading of grid infrastructures and appropriate EU regulations for grid integration.

Large-scale test facilities / RD\&D for upscaling.

Better coordination of financial support schemes across the EU.

Specialised education programmes.

Support of innovation in SMEs.

\subsection{Solar Photovoltaics.}

\section{Description}

1) Sector: Power generation

2) Current market share: $0.1 \%$ of demand $3.4 \mathrm{GWp}$

installed capacity

3) State of the Art:

Small scale: commercialised

Large scale: Development

Thin films: Development

\section{Potential}

1) Baseline scenario

2020: $9 \mathrm{GWp}$

2030: $16 \mathrm{GWp}$

2) Potential penetration

2020: $65 \div 125 \mathrm{GWp}$

2030: $300 \div 665 \mathrm{GWp}$

3) Potential breakthroughs: Integration of thin films in buildings.

High concentration devices for large systems

\section{Barriers}

High cost of electricity.

Techno-economic issues.

Building integration.

Lack of skilled professionals.

Access to grid.

Regulations and administration.

Needs

$\mathrm{R} \& \mathrm{D}$

Development of a liberalised market.

Financial incentives.

Framework to facilitating exports.

\subsection{Concentrated solar power.}

\section{Description}

1) Sector: Power generation.

2) Current market share: $0 \%$ of demand $<100 \mathrm{MW}$

installed and/or under construction capacity.

3) State of the Art:

Parabolic trough: commercialised.

Central receiver: commercialised.

Dish receiver: Demonstrated.

\section{Potential}

1) Baseline scenario 2020-2030: 0 GWe

2) Potential penetration.

2020: 1.8 GWe in EU27 $\rightarrow$ 1.8 GWe with 55 TWhe imports.

2030: 4.6 GWe in EU27 $\rightarrow$ 4.6 GWe with 216 TWhe imports.

3) Potential breakthroughs: Higher temperature systems, low cost heat storage.

Process scale-up > 100 MWe.

Trans Mediterranean Grid infrastructure.

\section{Barriers}

High cost of electricity.

Lack of feed-in support in most EU country.

Equity shortage for demonstrating first of a kind project. Investments in grid infrastructure. 


\section{Needs}

Expansion of feed-in tariffs for CSP in the EU.

Risk sharing financing mechanisms for large scale demonstration and commercialisation projects.

R\&D and Demonstration.

Open EU market to CSP imports.

Investment in a trans-European and trans-Mediterranean Super grid.

Framework to build-up a global market.

\subsection{Solar heating and cooling.}

\section{Description}

1) Sector: Heat generation

2) Current market share $2 \%$ of demand 13 GWth

installed capacity.

3) State of the Art.

Small scale for hot water: commercialised Combi-

systems: Demonstrated

Cooling systems: Development

Medium temperature industrial systems: development

\section{Potential}

1) Baseline scenario

2020: 52 GWth

2030: 135 GWth

2) Potential penetration

2020: $90 \div 320$ GWth

2030: $200 \div 700$ GWth

3) Potential breakthroughs.

Integration in buildings Cooling.

Medium temperature systems for industrial applications.

\section{Barriers}

Heat storage.

Lack of financial incentives.

Building integration.

Lack of skilled professionals.

Regulations and administration.

\section{Needs}

R\&D in energy storage and materials research.

Financial incentives for the deployment of the technology.

\subsection{Hydropower generation. Large HPP.}

\section{Description}

1) Sector: Power generation.

2) Current market share: $9 \%$ of demand about $95 \mathrm{GW}$ installed capacity (non pumped storage).

3) State of the Art:

Large scale: commercialised.

\section{Potential}

1) Baseline scenario; 2020: $100 \mathrm{GW}$

2030: $100 \mathrm{GW}$

2) Potential penetration

2020: 101 $\div 108 \mathrm{GW}$ (refurbishment from 2005 park: $25 \div 50 \%$ ).

2030: 104 $\div 112$ GW (refurbishment achieved from 2005 park: $55 \div 85 \%$ ).
3) Potential breakthroughs.

Large scale refurbishment of existing facilities.

Power electronics for dynamic operations (e.g. pumped hydro storage).

\section{Barriers}

Lack of institutional support.

Complex regulations and administration.

Lack of support for R\&D and Demonstration.

Equity shortage for R\&D development and

Demonstration.

Social acceptance

\section{Needs}

Increased R\&D and Demonstration public support. Focussed and co-ordinated R\&D and Demonstration programme at the EU level.

Coherent, harmonised and conducive regulation and administration frameworks across the EU.

\subsection{Hydropower generation: Small HPP.}

\section{Description}

1) Sector: Power generation

2) Current market share:

$1 \%$ of demand

$11 \mathrm{GW}$ installed capacity

3) State of the Art:

Small scale: commercialised

Very small scale: Development

\section{Potential}

1) Baseline scenario

2020: $14.5 \mathrm{GW}$

2030: $15.5 \mathrm{GW}$

2) Potential penetration

2020: $14.5 \div 18 \mathrm{GW}$

2030: $16.5 \div 19 \mathrm{GW}$

3) Potential breakthroughs.

Advanced low/very low head turbines

Power electronics

\section{Barriers}

Lack of institutional support.

Complex regulations and administration.

Lack of support for R\&D and Demonstration.

Equity shortage of SMEs for R\&D development and Demonstration.

Social acceptance.

\section{Needs}

Increased R\&D and Demonstration public support. Focussed and co-ordinated R\&D and Demonstration programme at the EU level.

Coherent, harmonised and conducive regulation and administration frameworks across the EU 


\subsection{Geothermal.}

\section{Description}

1) Sector: Heat and power generation.

2) Current market share: Less than $1 \%$ of demand.

3) State of the Art: Heat pumps commercialised.

DH commercialised.

Enhanced geothermal power system RD\&D.

\section{Potential}

1) Baseline scenario;

2020: $1,0 \mathrm{GWe}$

2030: 1,3 GWe (heat not available)

2) Potential penetration

2020: $1 \div 6 \mathrm{GWe}$

2030: $1 \div 8 \mathrm{GWe}$

2030: $38 \div 42$ GWth

2030: $60 \div 70$ GWth

\section{Barriers}

Lack of appropriate legislation.

Lack of financial incentives.

Lack of clarity in administrative procedures, long permit time.

Lack of skilled professionals.

Lack of social acceptance.

Fragmentation of existing knowledge.

\section{Needs}

Coherent financial support mechanisms.

Additional incentives.

Appropriate regulations, standards, permit procedures

RD\&D support.

International collaboration and centralisation of existing

Knowledge.

Vocational and training programmes.

\subsection{Ocean wave power.}

\section{Description}

1) Sector: Power generation

2) Current market share: Null

3) State of the Art: Demonstrated $<1 \mathrm{MW}$, on-going up to a few MWs.

\section{Potential}

1) Baseline scenario;

2020: 0,9 GWe

2030: $1,7 \mathrm{GWe}$

2) Potential penetration

2020: $5 \div 10 \mathrm{GWe}$

2030: $10 \div 16 \mathrm{GWe}$

3) Potential breakthroughs.

Large scale testing to commercialisation.

Off-shore grid infrastructure.

\section{Barriers}

Cost competitiveness of ocean electricity.

High cost of technology learning.

Lack of dedicated engineering capacities and of private Investments.

Cost of off-shore grid and unavailability of on-shore grid.

Administrative and legislative.
Coastal use.

Needs

R\&D and Demonstration.

Coordinated approach at EU level.

Long term feed-in tariff and capital investment support.

Coastal management at EU level.

\subsection{Cogeneration of heat and power.}

\section{Description}

1) Sector: Power generation /District heating / Industry.

2) Current market share: $10 \%$ of demand $\sim 95 \mathrm{GWe}$ installed capacity.

3) State of the Art: Large/medium scale: commercialised. Micro-CHP, fuel cells: R\&D evaluation.

\section{Potential}

1) Baseline scenario;

2020: $160 \mathrm{GWe}$

2030: $169 \mathrm{GWe}$

2) Potential penetration

2020: $165 \div 185 \mathrm{GWe}$

2030: $195 \div 235 \mathrm{GWe}$

3) Potential breakthroughs.

Large/medium scale overhaul/replacement with higher

electrical and overall efficiency.

Biomass based CHP.

Heat storage/cooling.

\section{Barriers}

Lack of coherent policies in some MS.

Market liberalisation exposes short term profitability projects.

Market uncertainties about fuel and electricity prices.

Many (older) installations now operate with lower efficiency and uncompetitive costs level.

Correlation of heat and electricity demand.

Slow progress on micro-CHP development.

\section{Needs}

Improved efficiency across the sectors, especially electrical.

Improvements in bio-CHP technology.

Innovations on thermal (heat) storage technologies and improved cooling systems.

Performance improvement (technology \& economics) for heat distribution infrastructure for $\mathrm{DH}$.

R\&D, demonstration and financing small scale CHP (fuel cells and micro-CHP) that lead to their mass introduction. Support transition to decentralised energy supply.

\subsection{Zero emission fossil fuel power plants.}

\section{Description}

1) Sector: Power generation

2) Current market share: Null

3) State of the Art.

Individual components commercialised in smaller scales.

Overall, in advanced research and validation phase, ready to embark on large scale demonstration. 


\section{Potential}

1) Baseline scenario.

2020: $0 \mathrm{GWe}$

2030: $0 \mathrm{GWe}$

2) Potential penetration.

2020: $5 \div 30 \mathrm{GWe}$

2030: $90 \div 190 \mathrm{GWe}$

3) Potential breakthroughs.

Successful large scale demonstration projects by 2015 .

\section{Barriers}

Technology not demonstrated at large scale.

High cost of first-of-a-kind plants.

Unfavourable market and regulatory conditions.

Lack of supportive fiscal measures.

Lack of $\mathrm{CO} 2$ transmission and storage infrastructure.

Public acceptance.

\section{Needs}

Research and development.

Large scale demonstration projects.

Development of a suitable regulatory and market

framework.

Development of $\mathrm{CO}_{2}$ transport and storage infrastructure

\subsection{Nuclear fission power.}

\section{Description}

1) Sector: Power generation (Gen- IV with heat generation).

2) Current market share: $31 \%$ of demand $\sim 135 \mathrm{GWe}$ installed capacity.

3) State of the Art.

Gen-III: Mature technology.

Gen-IV: depends on concept. Basic research still required for all designs leading to strategic decisions by 2012 at the latest. First of a kind and demo plants (VHTR and SFR) by 2020.

\section{Potential}

1) Baseline scenario.

2020: $114 \mathrm{GWe}$

2030: $100 \mathrm{GWe}$

2) Potential penetration.

2020: $127 \div 150 \mathrm{GWe}$

2030: $127 \div 200 \mathrm{GWe}$

3) Potential breakthroughs. To maintain market share requires c. $100 \mathrm{GWe}$ new build over next 25 years (GenIII).

Development of fast reactors and fuel cycles will enable much greater sustainability.

\section{Barriers}

Lack of overall EU nuclear strategy.

Lack of harmonised regulations and standards.

Public/political acceptance.

Insufficient public R\&D funding for Gen-IV.

Future availability of suitably qualified scientists and engineers.

\section{Needs}

A stable and predictable regulatory / economic / political environment.
Clear EU nuclear strategy Increased support for RDD\&D on Gen-IV; more public funding, public-private partnerships, Joint Undertakings, etc.

Better public and stakeholder information and dialogue on nuclear energy Promote education and training in scientific disciplines in general and nuclear technology in particular.

\subsection{Nuclear fusion power generation.}

\section{Description}

1) Sector: Power generation.

2) Current market share: None.

3) State of the Art: Committed construction of ITER as prototypic experiment aimed at demonstrating the technological feasibility of fusion energy.

\section{Potential}

1) Baseline scenario. N.A. before 2030.

2) Potential penetration. After 2030.

3) Potential breakthroughs. Operation of DEMO as demonstration fusion power plant.

\section{Barriers}

Limited industrial contributions to the financial sources due to the long-term nature.

Low availability of suitable trained engineers and scientists S\&T challenges on frontier technologies.

\section{Needs}

Strengthen the organisation of fusion development with reinforced industrial participation, in particular within the DEMO design group.

Reinforcement of education and training programmes. Strong political will for shortening the timescale of fusion development through EU 1 and international resources

\subsection{Electricity networks (smart grids).}

\section{Description}

1) Sector. Power transmission / distribution.

2) Current market share. $75 \div 85 \%$ of generation at transmission level $7 \div 10 \%$ of electricity consumed lost at transmission and distribution levels.

3) State of the Art. Long overhead lines Centralised network control.

\section{Potential}

1) Baseline scenario. New generation partially constrained by network bottlenecks.

2) Potential penetration.

2020: $1 \%$ losses reduction

2030: $2.5 \%$ losses reduction

3) Potential breakthroughs. HVDC, FACTS,WAMS

Active network management of distributed generation systems.

\section{Barriers}

How to define/share reinforcement and connection cost between stakeholders under discussion. Regulatory framework. 
Social oppositions.

Lack of coordinated research efforts.

\section{Needs}

EU Member States need to invest at least 400-450 b€ in transmission and distribution infrastructures over the next three decades.

Depending upon distance between new generation and a robust grid (e.g. off-shore wind, concentrated solar power), a further 10 to $25 \%$ share of connection costs may add to the global grid investment.

Shared design for integrating new generation technologies.

ICT for control and monitoring.

Standard rules and guidelines.

\subsection{Biofuels.}

\section{Description}

1) Sector: Transport.

2) Current market share: $3.9 \mathrm{Mt}$ of biofuels in 2005.

3) State of the Art.

1st generation: Commercialised

2nd generation: pilot scale demonstrated

\section{Potential}

1) Baseline scenario.

2020: $7.5 \%$ of transport petrol \& diesel demand.

2030: $9.5 \%$ of transport petrol \& diesel demand.

2) Potential penetration.

2020: $10 \div 14 \%$ of transport petrol \& diesel demand.

2030: $15 \div 20 \%$ of transport petrol \& diesel demand.

3 ) Potential breakthroughs. 2nd generation large scale demonstration by 2015 .

\section{Barriers}

No structural barriers.

Biomass availability and sustainability (including allocation between energy sectors and competition with non-energy sector).

\section{Needs}

Reinforced and focused public support for R\&D at national and EU levels.

Funding mechanisms for large scale demonstration initiatives.

Harmonisation of markets, regulations and policies at EU levels.

\subsection{Hydrogen and fuel cells.}

\section{Description}

1) Sector: Transport and Power generation.

2) Current market share: Null.

3) State of the Art.

Large scale hydrogen production: commercialised or under development.

Small scale H2: Demonstration/Commercialised.

Fuel cells: Demonstration.

\section{Potential}

1) Baseline scenario.

2020 - 2030: $0 \%$ of passenger cars.

2) Potential penetration.

2020: $1.5 \%$ of passenger cars.

2030: $6 \%$ to $12 \%$ of passenger cars.

3) Potential breakthroughs.

Low cost, reliable and durable fuel cells.

High capacity hydrogen storage.

Low cost and large scale carbon free/lean H2 supply.

\section{Barriers}

Long term and disruptive mitigation option.

Lack of end-use deployment support.

Regulation and Code and Standards.

High up-front infrastructure investments for hydrogen production and supply.

Shortage of equity for SMEs.

High cost of fuel cells.

Pending issue of primary resources allocation for hydrogen production.

\section{Needs}

Focussed R\&D and large scale Demonstration and market preparation efforts at EU level.

Long term public and private partnership.

Establishment of regulatory and financial support schemes.

Education.

\section{Conclusions}

The transition towards an economy of the coal of low levels of emission foresees execution time of at least two decades and it will affect to diverse sectors of the economy. The assumed decisions next 10-15 years will have deep consequences for the safety of energy, for the climate change, for growth and work places in Europe.

Need to plan the energy policies in the long term to a minimum of 10 years before, being even advisable that, in certain sectors, establish programs of performance to 40-50 years.

The strategic decisions formulated in the current moment must guarantee the attainment of the targets to be fulfilled in 2020 and the vision of the state of the energy sector in 2050.

Establishment of three axes of action:

(a) Design of a global strategic Plan agreed by the totality of the member countries promoting the programs of Joint Action (JA) and encouraging strategic projects assumed like proper for the EU to the margin of individual programs of the member countries.

(b) Incorporation of the renewable energies in the energy mix.

(c) Need to design policies and performances of $\mathrm{R}+\mathrm{D}+\mathrm{i}$ that guarantee the optimization of the technological processes linked to the Renewable Energies guaranteeing their competitiveness opposite to other energy sources. 


\section{References}

[1] IP/07/1750

[2] MEMO/07/469 Why Europe needs a Strategic Energy Plan.

[3] MEMO/07/493

[4] Monitoring progress towards Gender Equality in the Sixth Framework Programme. EUR 23341 ISSN 1018-5593 Catalogue KIND-23141-EN-C ISBN 978-92-79-08509-3

DOI 10.2777/60446 (2008)

[5] Innovation and transfer of results of energy RTD EUR 23122 ISSN 1018-5593. Catalogue KI-NA-23122-EN-N ISBN 978-92-79-07823-1 DOI 10.2777/34665 (2008).

[6] Redondo Gil, C.; Components of a policy energetic sustentable Carbon Funds. International Conference on Energetics 2007. ISBN 978963-420-908-9. Budapest University of Technology and Economics Budapest (Hungary), Junio 2007.

[7] CO2 Capture and Storage Projects, EUR 22574 ISSN 1018-5593 Catalogue KI-NA-22574-EN-C ISBN 92-79-03724-2 (2007).

[8] A Strategic Research Agenda for Photovoltaic Solar Energy Technology ISBN 978-92-79-05523-2 (2007).

[9] Fundación Centro de Supercomputación de Castilla y León (FCSCCYL) http://www.fcsccyl.es

[10] $3^{\text {rd }}$ International Conference on Integration of Renewable and Distributed Energy Resources. Nice (France) |December 10-12, 2008.

[11] The United States Department of Energy's Nuclear Energy Research Advisory Committee (NERAC) and the Generation IV International Forum (GIF) have issued "A Technology Roadmap for the Generation IV Nuclear Energy Systems"

[12] Monitoring progress towards Gender Equality in the Sixth. Framework Programme. EUR 23341 ISSN 1018-5593. Catalogue KIND-23141-EN-C ISBN 978-92-79-08509-3. DOI 10.2777/60446 (2008).

[13] www.eurocontrol.int/sesar/

[14] European Fuel Cell and Hydrogen Projects EUR 22398 Catalogue KI-NA-22398-EN-C ISBN 92-79-02692-5 (2006).

[15] http://ec.europa.eu/energy/res/setplan/

[16] http://ec.europa.eu/eit/

[17] CO2 Capture and Storage Projects EUR 22574.

ISSN 1018-5593. Catalogue KI-NA-22574-EN-C

ISBN 92-79-03724-2 (2007).

[18] European funded research on Hydrogen and Fuel Cells review assessment future outlook. EUR 21171 ISSN 1018-5593. Catalogue KI-NA-23171-EN-N ISBN 978-92-79-06940-6 DOI $10.2777 / 41309$ (2008). 